\title{
Burden of Proof: Documentation of an HIV Prevention Program in Ghana
}

\author{
Kathleen Inglis Simon Fraser University
}

\begin{abstract}
Globally, HIV programs face pressure to document their accountability and achievements using "evidence-based" criteria or "monitoring and evaluation" ("M\&E"), yet little is known about how M\&E occurs on the ground or its social and political effects. This paper explores how NGO actors in Ghana experienced routine documentation of a USAID-funded HIV program. Drawing upon 20 months of ethnographic fieldwork, I illustrate how M\&E documentation reproduces hierarchical aid relations by engaging NGO actors to self-govern through unexpected strict adherence to documentation requirements. I explore institutional supervisors' frustration with their deference to documentation to further show how inequality is indirectly reproduced.
\end{abstract}

Keywords: documents, data, monitoring and evaluation, HIV prevention, NGOs, Ghana

Résumé : Au niveau mondial, les programmes de prévention du VIH sont soumis à des pressions pour documenter la redevabilité et les réalisations par le biais de critères «fondés sur des données probantes " ou « de suivi et d'évaluation » ( S\&E »). Néanmoins, on sait peu de choses sur la façon dont le S\&E se déroule sur le terrain et/ou sur les effets sociaux et politiques qu'il engendre. Cet article explore la perception que se font les acteurs des ONG ghanéennes de la documentation quotidienne d'un programme de prévention du VIH financé par l'USAID. À partir d'une enquête de terrain ethnographique d'une durée de vingt mois, l'auteure décrit la façon dont la documentation $\mathrm{S} \& \mathrm{E}$ reproduit les relations d'aide hiérarchiques en incitant les acteurs des ONG à s'autogouverner par le respect strict et inattendu des exigences documentaires. Elle étudie en outre la frustration que ressentent les dirigeants institutionnels obligés de s'en remettre à la documentation afin d'illustrer le processus de reproduction indirecte des inégalités.

Mots-clés : documents, données, suivi et évaluation, prévention du VIH, ONG, Ghana

\section{Introduction}

$\mathrm{O}$ rganisations around the world that administer HIV programs face pressure to demonstrate accountability and achievement using "evidence-based" criteria and a practice referred to as "monitoring and evaluation," or "M\&E." Donors and governing bodies want numeric data that speak to indicators of accomplishment, a means of accounting based in business management that prevails in the domain of HIV and the field of global governance more generally (Merry 2016). Monitoring and evaluation represent a defining feature of global health, which increasingly use metrics (Adams 2016). Major institutions like the Global Fund to Fight AIDS, Tuberculosis, and Malaria; the United States President's Emergency Plan for AIDS Relief (PEPFAR); and the Institute on Health Metrics and Evaluation imagine that metrics offer uniform and standardised dialogue about the performance of interventions, organisations and countries (Adams 2016, 6). National and supranational M\&E systems - structures of indicators, procedures, people and technology - are variously set up around the globe. Anchoring M\&E systems are documents: data-driven reports that create comparative global knowledge. In order for spatially and temporally scattered actors and institutions to monitor and evaluate programs, they must know about programs in comparable terms utilizing such documents.

Social scientists of "audit culture" and metrics have emphasised the underlying tension between the positivistic and managerial approach that prevails in monitoring systems but which fail to capture messy social realities (Adams 2016; Merry 2011; Power 1997; Rottenburg et al. 2015; Strathern 2000). Authors have also claimed that metrics create realities, including the phenomenon they claim to measure (for example, IQ), new categories, and the roles and identities of actors (Biruk 2012; Erikson 2012; Lorway and Khan 2014; Merry 2016; Sangaramoorthy 2012). Within the HIV literature, there is a growing body of ethnographic research on the 
grounded experience and social effects of metrics, but little is known about how "monitoring and evaluation" as a distinct practice actually occurs at the grassroots level, how it is experienced by users, or its social and political effects ${ }^{1}$ - that is, the ways that monitoring and evaluation is productive of actions and social relations that maintain or challenge existing conditions in HIV intervention. What is also missing is an inquiry into the way that the fundamental, material form of $M \& E$ that is routinely handled by users - the reporting documents - is experienced. How does the demand to document data influence what users do, their roles, habits and social relations? How do users take up and/ or challenge M\&E document work? Are there any consequences?

This paper examines how actors at Hope, ${ }^{2}$ a nongovernmental organisation (NGO) in Ghana, experienced the $\mathrm{M} \& \mathrm{E}$ documentation of a prominent HIV prevention program called BRIDGES, and the socially significant unintended effects of this documentation. BRIDGES, a five-year program funded by the United States Agency for International Development (USAID), was administered through a "big international NGO" (BINGO) and implemented by numerous smaller NGOs throughout the country. There were fundamental inequalities between these institutional players that $\mathrm{M} \& \mathrm{E}$ documents brought to the surface. Inequality set the stage for Hope to be exacting with documentation, taking it up in anticipatory ways not simply because of donor demand, but on their own accord. In what appears contradictory, senior supervisors at USAID and the BINGO criticised Hope's, and other NGOs', preoccupation with documentation despite having simultaneously created the conditions for it. I draw upon Mark Schuller's (2012) concept of "trickle-down imperialism" to explore the meaning of this contradiction. By focusing on Hope actors' experiences with $\mathrm{M} \& \mathrm{E}$ documentation, this paper shows how these kinds of documentation practices do not simply reflect but also produce social relations and habits, which can, as they did in this case, inadvertently perpetuate hierarchical aid relations.

BRIDGES was a globally standard program that focused on "most at risk populations," or "MARPS". These are communities of people regarded as the most vulnerable to HIV and as having higher prevalence rates. Under BRIDGES, these "target groups" included "female sex workers," "men who have sex with men," and "non-paying partners," an ambiguous term often defined to me by participants as males in a relationship with sex workers who do not directly pay money for sex, but who offer companionship, love, protection, and/or material support in the form of food, shelter, et cetera.
Some described them as "pimps." During 20 months of ethnographic fieldwork, I followed M\&E efforts to understand institutional practices set up to judge program efficacy. Following monitoring and evaluation largely turned out to mean following the course of M\&E documentation from the program community sites to the USAID/Ghana office. This entailed participant observation of frontline workers, called peer educators, in community sites where they were meant to record program activities as data. Peer educators, themselves members of "most at risk populations" and trained by Hope, communicated behaviour-change messages, sold condoms and offered referrals to the local clinic. Select individuals were certified to provide HIV testing and counselling. I also conducted participant observation of $\mathrm{M} \& \mathrm{E}$ document work at Hope's head office and obtained copies of documents as they moved from Hope to the BINGO to USAID/ Ghana. I attended program- and M\&E-related meetings, trainings and workshops at various sites, including Hope; the BINGO; the Ghana AIDS Commission; the University of Ghana; and hotels throughout Southern Ghana. I spoke formally and informally with program- and M\&Erelated personnel who held various positions. My participation in M\&E documentation deepened after some months when Eli, Hope's one and only M\&E officer, asked me to help him by inspecting the numerical accuracy of peer educators' written data and by entering data into his Excel worksheet. The Norwegian volunteer who had previously assisted Eli had, like other foreign volunteers before him, gone home, and Eli was overwhelmed with data. I completed these tasks in a cubicle in Hope's office. From these methods, I gained insight into routine $\mathrm{M} \& \mathrm{E}$ documentary practices and processes (largely from Hope's perspective) and how actors engaged with and regarded $\mathrm{M} \& \mathrm{E}$ documentation.

Following the documentation was not about observing people chasing data down to a predetermined finish line, which upon reaching they would be done, ready for the next task. Rather, Hope actors felt the pressure to document "around." That is, they constantly anticipated the need to document. M\&E documentation in this sense is a site of anticipatory practice whereby "the future is inhabited in the present" (Adams et al. 2009, 249). Anticipating M\&E documentation configured to some degree their work and roles in the present. Metrics, therefore, do not act alone in their reality construction; (anticipating) the tangible exercise of documenting data to answer to metrics co-constituted users' roles and what they did. Scholars have argued that audit technologies (reports, indicators) are new forms of governance that engage actors in self-monitoring (Strathern 2000; Shore and Wright 2015a, 2015b). As such, actors 
become active participants in their governing as opposed to being objects of external domination (Rose 1989). This paper augments this analytical point by showing that, in Hope's case, M\&E documents engaged actors in governing themselves in ways that were unexpected and objected to by USAID and the BINGO, which entrenched unequal power relations. I therefore join with other ethnographers of documentary practices who seek to provide a greater sense of the landscape of document work as experienced by those within it as a means of gaining insight into the practices of contemporary forms of governance on the ground.

\section{Aid and Accountability}

One afternoon, in one of two side-by-side, one-storey buildings occupied by Hope, the BRIDGES data collection booklets were piled high on my desk in the cubicle where I worked. The booklets contained pages of a grid template; peer educators had filled about half the pages with handwritten numbers that represented monthly accomplishments. Blank templates awaited completion in the months ahead. I sat perpendicular to $\mathrm{M} \& \mathrm{E}$ officer Eli, who sat in a centrally situated desk. A breeze from the window periodically hit my back, a welcome treat as the ceiling fans hung motionless from another power outage. Hope's director, Aunty Phyllis, stopped in from the adjacent building for a mid-day social chat. With her arms leaning on the top edges of my cubicle, she peered at my messy tabletop. My laptop was open to an Excel spreadsheet created by Eli; scrap paper covered with my math-checking scribbles littered my desk. Frowning, she said, "I'm glad that you are learning what we have to do for them. You are seeing for yourself. It's all about figures with them - are you seeing it!" She waved her hand, annoyed. Eli snickered.

By "them" Aunty Phyllis was referring to the donor, USAID. NGOs also report to the Ghana AIDS Commission (GAC), a supraministerial policy-making body on HIV and AIDS under the Office of the President. GAC oversees a country-level M\&E system that foreign and Ghanaian organisations are meant to adhere to, regardless of whether GAC provided their funding. The countrylevel M\&E system was set up in accordance with a 2004 international agreement, the "Three Ones," initiated by the Joint United Nations Programme on HIV/AIDS (UNAIDS) with the World Bank and the Global Fund (World Health Organization 2017). The agreement was part of a policy upsurge in principles such as "country ownership," "coordination" and "harmonization." USAID and GAC both required reports that demanded similar information, largely quantitative, albeit using different reporting templates and channels.
USAID, which has a history with Ghana dating back to the 1960 s, has provided aid across various sectors and has been a major donor presence for HIV and AIDS activities since the 1980s. Ghana's relatively low HIV prevalence rate, currently at $1.6 \%$ (World Bank Group 2017), has led USAID's programmatic focus on "most at risk populations," seen as the "drivers" of the epidemic an approach thought to make the best use of resources. HIV efforts, epidemiological in nature, focus on keeping rates low and "contained." At events and trainings I attended, speakers commonly warned of rampant infection if efforts waned, citing the reversal of various African countries' success stories, such as Uganda's, as examples. Donald Teitelbaum, former American ambassador to Ghana, stated at the 2011 World AIDS Day celebration that Ghana was "a tremendous success story" but that "this was no time to be complacent ... the US will be there with you."

USAID and the Global Fund have historically made up the majority of funding for HIV and AIDS. During my 2011-2013 fieldwork, around three-quarters of funding for HIV and AIDS came from abroad (Ghana AIDS Commission 2015, 114-115). Organisations in Ghana are heavily reliant on external funding. Hope, for instance, is entirely dependent on donor funding. USAID and the BINGO, which was awarded BRIDGES, subcontracted Hope. NGOs are compelled to continually show, via $\mathrm{M} \& \mathrm{E}$ documents, that they are meeting their targets to ensure yearly funding renewal (non-renewal does not happen lightly, however).

This aid and accountability system is rooted in postcolonial relations. Following colonialism and then independence in the 1960s and 1970s, donors in the Global North blamed Africa's so-called state of underdevelopment on corruption, authoritarianism and large state bureaucracies while touting "the market," a reduced role for the state and an increased role for an autonomous "civil society" as the way out (Yarrow 2011). These recommendations formed the basis of the economic reform packages called "structural adjustment programs" (SAPs), imposed upon African governments and other developing countries as a condition for their receipt of loans from the World Bank, the International Monetary Fund and other donors. Many African countries, including Ghana, devised major "free market" economic policy reforms in exchange for much-needed financial assistance in the face of deepening economic crisis and debt (Mawuko-Yevugah 2014, 43). These neoliberal policies led to a surge of NGOs across sub-Saharan Africa and the world during the 1980s and 1990s. By then, NGOs were experiencing increased issues of accountability (Harsh et al. 2010). As non-profit and non-governmental 
organisations mushroomed in many parts of the world, they have also been besieged by scandals, including appropriating funds for personal gain, and fraud (Ebrahim 2003). A loss of confidence in NGOs led not only to donor but also to public demand for increased accountability and transparency - or "audit culture." Across many domains, there has been a demand for actors and organisations to show tangible and calculative proof of their actions so that others can examine the stages involved in decision making to ensure that they are acting responsibly, and to ensure program efficacy. USAID itself submits reports to Congress under the guise of transparency, "efficiency, effectiveness, and accountability to the U.S. taxpayer" (USAID 2017).

HIV programs have been subject to justifying expenditures and demonstrating their effect through these practices of evaluation. Responses in the 1980s were somewhat ad hoc, owing to the onset of the looming threat of this new and unfamiliar disease spreading and to a sense of urgency to respond (De Lay and Manda 2004; Rugg et al. 2004). Prevention programs were often implemented without a plan or staff for baseline research or for monitoring and evaluation, including in Africa - much to the chagrin of HIV and AIDS experts who called for greater efforts to evaluate these programs (see Coyle et al. 1991). With the neoliberal shift that has put NGOs in charge of public health services, a lack of evaluation capacity led to what was seen as poor evaluation (not to mention that NGOs' existence depended upon showing positive results, so there was good reason for some of them not to use evaluation in the standard way). There came a shift from evaluation being something thought about at the end of a program to a strategy of constant monitoring. Tracking a program and collecting data for reporting purposes have become a daily practice for many NGOs endeavouring to legitimise their existence.

Developing countries' continued dependence on foreign donors is a legacy of structural adjustment, which not only failed to eradicate poverty but exacerbated countries' debt and their inability to provide basic social services (Mawuko-Yevugah 2014, 43). Although the age of optimism about NGOs may have softened, they have remained an important and widespread presence in development (Harsh et al. 2010). By one count, there were 5,298 NGOs in Ghana in 2013 (Awuah-Werekoh 2014). ${ }^{4}$ Now they are referred to as "implementing partners," as part of the wider development discourse of "partnership," which are specifically emphasised in HIV programming (Esser 2015). Partnership discourse, alongside that of "country ownership," is meant to represent a power shift in the aid relationship from a donor-led relationship to one that is recipient-led (Esser 2015; Mawuko-Yevugah 2014). Calls for partnership and participation by actors within recipient countries are the current trend (discussed below). Ghana has been viewed as an attractive "partner" for donors, reputed to be a neoliberal "donor darling" that has welcomed foreign investment (Hodžić 2016, 13), and proclaimed by Barack Obama to be "a model for democracy" in Africa (Karimi 2012). With persistent donor presence, M\&E documentation is increasingly commonplace. The investment in $\mathrm{M} \& \mathrm{E}$ documents as products containing "objective" numeric results diverts attention from the actual practices and processes that produce these documents and their implications. ${ }^{5}$ It is therefore my intention to contribute to the recent anthropological project of making ordinary, invisible documents and documentation procedures visible (Hull 2012).

\section{Documentation Ritual}

Once a month, Hope's peer educators gathered at tables under the shade of trees in Hope's courtyard to fill out their "Daily Activity Sheet," which I refer to as "the Sheet" (see Figure 1).

The Sheet summarised peer educators' monthly activities in the form of check marks, letters and numbers. Required information about interactions with community members was listed in the columns, including date; unique identification code (UIC), a numeric code that identifies the person; new or old contact; sex; age; oneon-one or small group interaction; services and information provided, including the number of condoms and the amount of lubricant sold, messages about tolerance and stigma, abstinence, being faithful, using condoms (ABC), ${ }^{6}$ sexually transmitted infections (STIs), counselling and testing services (CT), gender-based violence services (GBV), and any other services; and lastly, referrals provided.

The Sheet was adhered within a one-inch-thick carbon-copy book belonging to the peer educator, which sat on a shelf in the Hope office. In anticipation of filling out the Sheet at the month-end meeting, peer educators recorded their daily activities as raw data in a Hopesupplied field notebook, which they later transferred to the Sheet. From morning to afternoon at the meeting, and sometimes into early evening, peer educators hunched over their sheets, tediously tallying their check marks, letters and numbers with shared calculators, working back and forth between the Sheet and their notebook, making sure both documents matched. Some ripped pieces of scrap paper from their notebooks to calculate 


\section{Peer Educators Daily Activity Sheet}

\section{Name of Organisation:}

Region:

District:

Location:

Year:
Target Population: MSM $\square$ MSW $\square$ FSW $\square$ Non-PP $\square$ PLHIV $\square$

\begin{tabular}{|c|c|c|c|c|c|c|c|c|c|c|c|c|c|c|c|c|c|c|c|c|}
\hline \multirow[b]{2}{*}{ Date } & \multirow[b]{2}{*}{$\begin{array}{c}\text { UIC } \\
\text { CODE }\end{array}$} & \multirow{2}{*}{\begin{tabular}{|c|} 
Type \\
Old/New
\end{tabular}} & \multirow{2}{*}{\begin{tabular}{|l|} 
Sex \\
M/F
\end{tabular}} & \multirow[b]{2}{*}{ Age } & \multicolumn{2}{|c|}{ Approach } & \multicolumn{9}{|c|}{ Services } & \multicolumn{5}{|c|}{ Referral } \\
\hline & & & & & $\begin{array}{l}\text { One } \\
\text { on one }\end{array}$ & \begin{tabular}{l|} 
Small \\
group
\end{tabular} & ABS & STI & $\mathrm{CT} C$ & GBV & $\begin{array}{l}\text { Condor } \\
\text { Male }\end{array}$ & $\begin{array}{l}\text { Ims Sold } \\
\text { Female }\end{array}$ & $\begin{array}{l}\text { Lubs. } \\
\text { sold }\end{array}$ & Stigma & Other & STI & CT & Psycho & GBV & Other \\
\hline & & & & & & & & & & & & & & & & & & & & \\
\hline & & & & & & & & & & & & & & & & & & & & \\
\hline & & & & & & & & & & & & & & & & & & & & \\
\hline & & & & & & & & & & & & & & & & & & & & \\
\hline & & & & & & & & & & & & & & & & & & & & \\
\hline & & & & & & & & & & & & & & & & & & & & \\
\hline & & & & & & & & & & & & & & & & & & & & \\
\hline & & & & & & & & & & & & & & & & & & & & \\
\hline & & & & & & & & & & & & & & & & & & & & \\
\hline & & & & & & & & & & & & & & & & & & & & \\
\hline & & & & & & & & & & & & & & & & & & & & \\
\hline & & & & & & & & & & & & & & & & & & & & \\
\hline & & & & & & & & & & & & & & & & & & & & \\
\hline & & & & & & & & & & & & & & & & & & & & \\
\hline & & & & & & & & & & & & & & & & & & & & \\
\hline & & & & & & & & & & & & & & & & & & & & \\
\hline
\end{tabular}

PE code (UIC):

Signature/ Date:

Figure 1: Peer educators' Daily Activity Sheet (the Sheet) (document courtesy of BRIDGES)

manually. Those more confident used a pen, while those less assured used a pencil and penned over their calculations in their final edit. Hope's field staff members, Akua and Francine, circulated, making themselves available for data entry and calculation questions, as would I. Those more skilled would help others, supervising over their shoulder or helping them to work backwards from their notebooks when they could not figure out why the checks, letters and numbers did not align.

Eli approved and signed off on all of the Sheets. Peer educators could not leave for the day until their Sheet was signed. The office screen door slammed open and shut throughout the day as one by one peer educators opened their books to the appropriate sheet and handed it over to Eli. They waited patiently, and some- times impatiently, as he took his time cross-tabulating each and every row and column. Eli either signed the Sheet or would tell them to go back and edit if dataentry errors had been found, which he determined by asking himself the following kinds of questions: "Are all the check marks in place?" "Do the numbers make sense?" If the answer to the latter question was "no," other questions would arise, such as "Why are all the reported ages of a peer educator's contacts coincidentally nineteen years old?" or "Are they 'cooking' data?"

Every month Eli electronically amalgamated the Sheets into numeric data in an Excel spreadsheet. He did this for all the districts in Ghana where Hope carried out the BRIDGES program. Geographic distance prevented Eli from personally collecting the data from 
every district, so senior staff members at district offices emailed the data to him. Eli then sent his Excel document to the BINGO. The BINGO received electronic documents of this type from all the NGOs across the country that were carrying out the program. Personnel at the BINGO themselves spent a good deal of time checking these numbers - at times referring back to the NGO if they caught a data-entry mistake - then amalgamating the numbers into another Excel spreadsheet. They also provided concise explanations of any noteworthy numbers, such as overachievements and underachievements, directly beneath a set of figures. This document was emailed to USAID/Ghana, where a senior advisor and prevention officer looked over the data, referring back to the BINGO if necessary with discrepancies, questions or other concerns before sending it on to USAID/Washington's headquarters. Equally demanding quarterly and annual reports required similar processes of documentation.

$M \& E$ documentation entails a set of nested processes from which an incrementally wider perspective of the program is gained. As an advisor from the BINGO put it, the process allows "a bird's eye view of the program." In order that each layer can be embedded within the next, the process relies on representations of the program that, to use Latour's terms (1987), carry the properties of being mobile (can travel over far distances), immutable (the meaning stays relatively intact as it travels), and combinable (can be aggregated) (see also Rottenburg 2009, 181-182). This process enables donors, and the BINGO, to "govern at a distance" (Miller and Rose 1990). The Sheet, designed by USAID and the BINGO, was specific to the BRIDGES program, but similar templates exist for HIV prevention programs the world over; they are evidence of $\mathrm{M} \& \mathrm{E}$ standardisation - a process that might be defined as "constructing uniformities across time and space, through the generation of agreed-upon rules" (Timmermans and Epstein 2010, 71). For instance, there was a Global Fund program in Ghana happening at the same time as BRIDGES that used a very similar daily activity sheet.

This entire documentation procedure is not simply routine practice, but is in part a moral process that "transformed" raw numbers into meaningful and useable information (Harper 2000), and a principal means by which peer educators regard their role and relationship with donors, shown below. It has, in this respect, rituallike and symbolic dimensions that helps to produce patterns of inter/action and which structure power relationships. Rituals of bureaucratic order and "organisational culture" have attracted scholars for some time, but it is only fairly recently that the practice of documentation as symbolically significant has been given focused attention (Hull 2012). I aim to contribute to such scholarship by viewing M\&E documentation as entailing an element of a political ritual that "as a medium of communication and interaction does not simply express or transmit values and messages but also actually ... create[s] power in the very tangible exercise of it" (Bell 2009, 232-233).

At one meeting, peer educator Prince complained as he paced around fellow peer educators filling in their Sheets: "Eh! Data, data, data, all day data! ... When do we see donors, hmm? When? ... When do we see donors in the field? All they want is data and our books ... I will be here until laaaaaate." On another occasion, while filling in her Sheet, peer educator Victoria tsked and said to me, "Sometimes it's like this is all I'm good for." "What?" I asked. "This." Victoria lifted her booklet without looking up. "[Donors], they say they want data and we jump, filling [the Sheets] out for them always ..." It was not uncommon for peer educators to grumble about data collection, Sheet-filling and their role as data producers for donors, whom they regarded as ultimately in control, although they recognised the power of the BINGO too. Filling out the Sheet at times produced a sense of alienation among peer educators. The Sheet served as symbol of the literal and figurative distance between peer educators and the donors. When Prince facetiously asked, "When do we see donors?" he was alluding to the fact that the Sheets were the peer educators' only mode of regular "interaction" with donors. Donors were chiefly seen through a symbolic form, which for peer educators established their relationship as unidirectional and one of dominance and subordination. It was not only in the moment of Sheet-filling that peer educators' roles and positions were constructed; these were also created when they were anticipating the arrival of the Sheet.

As peer educators worked, the Sheet loomed over them. Typically, peer educators congregated in the late morning in their Hope-assigned community, an epidemiological "hotspot" mapped as a key location where MARPS conducted sex work, resided and/or hung out. Equipped with education materials in their bags pamphlets with "key health messages," a picture book of STIs, small booklets with contact information - peer educators strolled about the community looking for people to approach. The program gave peer educators monthly quotas, or "targets," of people they needed to "reach." Some walked around the community frustrated, trying to find new MARPS so that they could write enough "N's" (for "new" contacts) on the Sheet by month end. One morning in a suburban "slum" crammed with plywood homes roofed with corrugated metal, crowded tenement buildings, small shops, bars ("spots") and a 
large market, I walked alongside Harmony in the group. Harmony, wearing her bright-green Hope polo shirt, walked with purpose through the maze of dirt pathways; our feet dodged litter and puddles. I asked her what her plan was for the day. She replied that she needed to "get a lot" of new female sex workers to reach her target. She made a beeline for two young women chatting in a laneway as the rest of us continued on, some breaking off to approach other community members. Some minutes later Harmony caught up to us and, slowing from her jog, said, "Whew, that's two!" At the day's end I asked if her day had gone well. She replied that it had been "okay" because she ended up interacting with "plenty" of new sex workers. I asked if it was stressful for her to meet targets. Furrowing her brow, she responded, "It is. Our aim is to achieve our targets, but it's like aaaaaah! And they will trouble you if you don't." In anticipation of submitting the Sheet, many peer educators regularly expressed the strain they were feeling about meeting targets. Occasionally peer educators and Hope staff used language that connoted catching people: "getting" people, for example, as Harmony stated above. It was not uncommon to hear phrases like "I got three" and "We can get more if we go over there." One month, Prince - who had been absent for more than a week was yelled at by field officer Francine on the day he returned: "You should get at least ten today, Prince, to make up for all the days you missed!" Peer educators were on a mission to document data, not just educate, and community members became the data - numbers to capture. In recounting these conversations, my aim is not, of course, to suggest that important education and prevention awareness did not get done; rather, it is to bring attention to the ways that M\&E documentation helps shape what NGOs, peer educators and community members become in the process of doing this work.

Peer educators were forewarned in meetings that underachieving would lead to their dismissal. While these people are passionate and skilled at their jobs, it was not uncommon for some to interact half-heartedly and quickly with a person just so they could be documented. Although officially peer educators were "volunteers," many looked forward to the monthly "T and T" transport and travelling - "payment" of 30 cedis, approximately $\mathrm{CAD} \$ 8.50$, or half of what constitutes a poverty-line wage in Ghana (Cooke et al. 2016), an amount that could supplement their salary if they had other work. Some also wanted to boost their CVs because they were aspiring to a career in social work or development. The threat of dismissal was, therefore, not insignificant.

The Sheets were a material prompt to peer educators of their role in the program as target achievers and data producers, not as creators or collaborators. The reduction of peer educators, or community health workers more generally, to ill-paid, low-level tools or "mere [costeffective health care] delivery mechanisms" for health programs (Maes 2017, 9) is an upshot of structural adjustment programs. Government payroll cutbacks and the promotion of NGOs to take over public health services were seen as the way forward, but donor funding of NGO payroll expenditures was regarded as financially unsustainable; therefore, unpaid community-based health care became the model in developing countries (Maes 2017, 25). How the relatively powerless position of community health workers continues, and is challenged, is an emerging scholarly subject (Maes 2017). M\&E documentation may perpetuate their subordinate position by establishing their role in part as data documenters for higher powers rather than as creators and controllers in the design and implementation of social policies and programs.

$\mathrm{M} \& \mathrm{E}$ documentation did not totally disempower peer educators, however. They still expressed pride and joy in helping marginalised persons and preventing HIV. As peer educator Naomi explained, "It's important, what we do: reaching people, helping people, preventing disease. Sometimes you go home with a smiling face." Nor was their work fully represented by the columned classifications in the Sheet. For example, peer educator Viola went for walks with a man living with HIV, accompanied individuals to clinics at all hours, and lent her STI book (containing images of physical signs of STIs) to her pastor friend, who used it in her educational sermon.

Although peer educators had pride in their work and some autonomy, they were critically aware of their role as low-paid labourers and data collectors. Prince was especially frustrated by power inequalities. In an interview he banged his fist on the table as he angrily stated, "I mean, BRIDGES will be demanding data from you and then we're barely paid!" Viola, who was relatively new, shared that she had learned rather quickly "not to make noise" after her pastor friend borrowed her STI book for her sermon:

After [the sermon] a bunch of people were coming up to her saying they had symptoms. She asked if our team could come to their village and test [for HIV] and educate and give referrals. I told Francine, who said she'd tell Aunty Phyllis, but I never heard anything again. So I myself, I just keep low, 'cause it's as if I'm the one pushing, but I can't see the effect coming. So I just let it go. I just keep doing what I'm doing and collecting and writing the data they want at the end of the month and that's it [shrugs]. 
There are various possibilities as to why Aunty Phyllis did not follow up with Viola, including not wanting to venture out of Hope's donor- and BINGOdesignated community sites. What is telling is that, in the same breath, Viola associated toeing the line with a focus on her role as M\&E data collector/documenter rather than as someone who develops ideas, organises and implements them. This is not to say that these are inherently mutually exclusive realms or that this is the intention of the Sheet designers - the donor and the BINGO. What is of interest here is that M\&E documentation had an effect on how peer educators regarded themselves and their position within the BRIDGES hierarchy, reifying power relations. In addition, Viola's account touches on my research finding that the general regard for peer educators as low-level labourers and predominantly target achievers came not simply or directly from USAID and the BINGO, but also from those within Hope.

\section{The Sheets as "Receipts"}

Frustrated with peer educators' technical errors in the Sheets, Aunty Phyllis and senior staff at Hope decided that the peer educators needed greater discipline, so they standardised the notebook format. Peer educators were originally meant to carry small notebooks to the field to discreetly jot down raw data. They were also meant, a BINGO advisor told me, to write down any thoughts or feelings about the program or what transpired. They were also encouraged by the BINGO to sketch drawings, particularly if they found writing challenging. To smooth the documentation process, however, Hope took it upon itself to alter the original intention of maintaining a diary-like notebook format. Instead, peer educators were instructed to trace out, with a ruler or the edge of a book, an exact miniature version of the Sheet in a larger notebook (see Figure 2).

At the January meeting when the standardised notebooks were introduced, Aunty Phyllis reprimanded the peer educators. "One standard!" she pronounced, pausing for dramatic effect. Then, rhythmically pounding her fist in her lap, added, "Standardisation! Standardisation!" Eli then said, "Your notebooks are your receipt. In the work that we are doing, there are standards. It's a system we are implementing ... Even in my personal life when I buy something I have a receipt so nobody can accuse me of stealing the phone." An M\&E officer from another NGO assisting with the meeting that day added that "gaps" in the Sheets were still an issue. "We don't want them making noise," he said. "We don't want anyone to raise any doubts about what we're doing ... That is the business of M\&E."

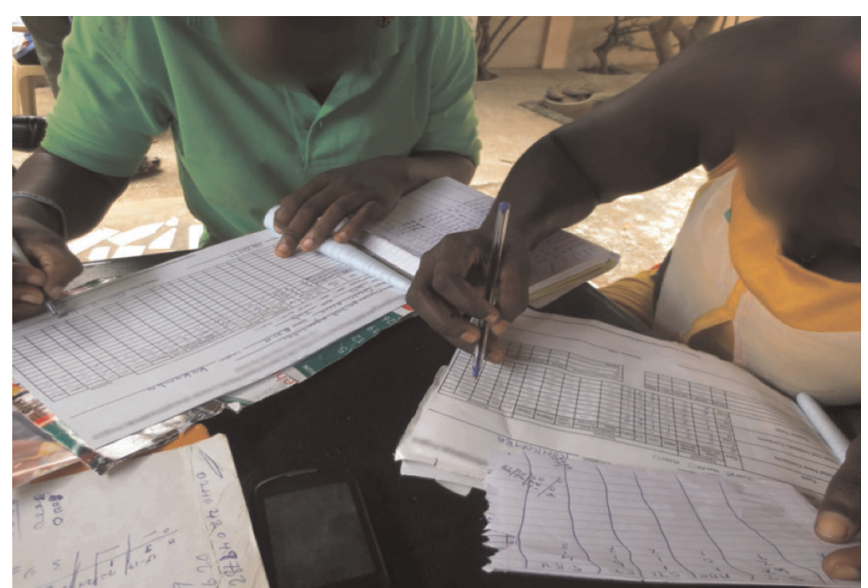

Figure 2: Peer educators filling in the Sheet from their raw data (author's photograph).

Hope treated the Sheets as a form of surveillance. The portrayal of the Sheets as "receipts" indicates their given purpose as preventing and catching idleness. Peer educators were regularly put in the position of using the Sheets defensively. Under the guise of enumeration, the Sheets signalled if they were underachieving and at risk of getting in trouble. The underlying tone of suspicion shows that M\&E documentation operated as obligatory acts to prove one's guiltlessness. Peer educators knew that $\mathrm{M} \& \mathrm{E}$ was not about their experiences and knowledge; monitoring and evaluation was not for them. It was about completing an artifact to send up the hierarchy for approval. The Sheets suggested a lack of trust, which established the marginal status of peer educators, and were also a principal medium through which Aunty Phyllis and Hope staff understood their organisation's role within the institutional hierarchy. The Sheets as receipts marked Hope's understanding of their institutional relationships as based on liability and business, whereby they owed proof of program delivery (number of "targets" achieved) in exchange for funds. The Sheets as receipts helped to assert the subservient status of those working at Hope and their role as "mere delivery mechanisms" of the program (Maes 2017, 9) and not "local partners," as they were called within BRIDGES discourse.

For peer educators, the conceptualisation of monitoring and evaluation as documentary obligation to prove one's credibility to higher authorities was solidified when Hope reminded peer educators that the purpose of filling in the Sheets accurately was to prove that they were not "cooking data." At the same meeting, Eli told the peer educators, "We do this because maybe someone somewhere will think you're cooking your data! If you cook 
data, I will know!" Aunty Phyllis further warned them, "Some of you bring in data and right away I can tell. 'This is fake data!' and I will throw it away!"

I asked Aunty Phyllis and Eli in interviews whether peer educators were cooking data and why; both relayed that a few might be, out of incompetence and laziness, but overall they had gotten better with training and discipline. Their viewpoints failed to recognise that there is intentionality behind cooking data; it is different from unintentional deviations through technical error or carelessness (Kingori and Gerrets 2016). For instance, Prince candidly explained in an interview that peer educators' low pay (that is, their " $\mathrm{T}$ and $\mathrm{T}$ ") is why he cooks data:

Sometimes when I'm going to work, I feel like not going in, because ugh! Where is the money? And if you don't show up because you don't have anything in your pocket, they tell you you're a bad peer educator ... I mean, if you are a human being working, you are worth something. Why am I going to work then? But I can't give excuses or complain because [peer educators] are small from the top ... It has affected our attitudes. I can tell you that peer educators are cooking data, even including me, myself. Because where is the money to go again to talk to somebody and get data for you? No, no, no. So maybe I'll go some days, some days I will not go and I won't have data ... If you don't pay me but you expect data from me, then the data that is coming to you is cooked data! And I am fine with that.

I asked Prince, “Could you tell Hope, 'I didn't talk to a lot of people this month because BRIDGES didn't give me enough money?" Prince smirked. "Hmph. They don't care. So why should I care [about cooking data]?"

In response to not being treated like he is "worth something" and to feeling powerless to voice his opinions ("because peer educators are small from the top"), Prince resisted the only way he thought possible: by cooking data. Although M\&E documentation was a principal medium through which authority and deference were constructed, we see here that it was also a means for a peer educator to act under unfair conditions. Low pay was an impetus for cooking data, for it made it difficult to meet expectations, but Prince also conveys as a reason low morale due to a lack of institutional support and understanding ("you're a bad peer educator"; "They don't care"), in line with findings of Kingori and Gerrets's (2016) study of data fabrication among medical research fieldworkers in sub-Saharan Africa. Prince's perception of Hope's lack of understanding and care about peer educators' challenges influenced his attitude about cooking data, as reflected above. Prince is a spirited and compassionate peer educator; the issue here is not that Prince or peer educators who cook data are lazy or do so out of malice. Rather, talk about cooking data is a lens into peer educators' social reality - a reality that is a result of contradictions set up at the management end of the program and unaddressed by managers (Kingori and Gerrets 2016). This phenomenon is not at all specific to any NGO or indeed any peer educator, but is a concern for various institutional environments (Biruk 2018; Fisher et al. 2013; Kingori and Gerrets 2016; True et al. 2011), and institutional challenges thwarting accurate data collection have been noted for a long time (for example, Justice 1986).

The viewpoint of Aunty Phyllis and Eli, that peer educators need technical and moral disciplining through stricter adherence to the Sheet, obscures the "institutional and social conditions that enable and foster fabrication" (Kingori and Gerrets 2016, 151; see also Biruk 2018). Kingori and Gerrets (2016) make the astute argument that the ability to ignore or remain unaware of fieldworkers' challenges influencing data fabrication "is assisted by the contemporary configuration of research which favours the compartmentalization of tasks and personnel by hierarchy, division of labour and distance e.g., geographic, socio-economic" (158). The authors discuss the social and geographic distance between fieldworkers, "institutional headquarters," and "those designing projects and conducting data analysis" that "had limited insight into everyday fieldworker challenges" (158). But what does it mean when actors like Hope staff overlook the challenges faced by fieldworkers within their own institutions given that these actors do have some insight into the everyday situations their fieldworkers confront? Furthermore, what does it mean, analytically, when an NGO, on its own accord, strictly standardises field notebooks to act as receipts, which reaffirms its workers' role as subjects to be improved through training and discipline? I endeavour to address these questions in the next section.

\section{Blind Documentation Bind}

Supervisors at the non-NGO levels do not directly pressure NGOs to make M\&E documentation their focus. In fact, as John, a USAID/Ghana advisor explained, "Higher-level staff are concerned about the increasingly dominant and dictating role monitoring and evaluation plays." In an interview John expressed frustration that NGOs "blindly" follow the documentation criteria. "People can get obsessed," he said, and therefore "didn't think creatively. It's a matter of maturity. Just like a child needs to handle authority, rules and regulations so [they] don't go to jail all the time." He also noted 
that program implementers can learn to act independently within these rules. The sense that others shared John's frustration is palpable in the following example from a meeting comprising personnel from NGOs, the BINGO, USAID/Ghana, and the Ghana AIDS Commission. Higher-level personnel criticised a woman from an NGO for taking the M\&E forms too literally. She relayed that it was a challenge getting female sex workers to buy condoms sold under BRIDGES because a nearby Global Fund program was giving condoms away for free. John asked her why she had not tried to liaise with Global Fund program personnel to acquire free condoms. Confused, she explained that doing so would skew the "condoms sold" data and interfere with their targets, because there was no space in the M\&E documents to account for such proceedings. Below is a transcript of how higher-level personnel responded:

John: Sometimes people get too hung up on targets! Others chiming in: Yes! [nodding around the table]

John: Create an asterisk in your report that you got these condoms from [the other program].

Advisor, BINGO: Yes!

John: Targets are artificial constructs. The practical work is you try to prevent HIV. Don't stop doing important things because you have targets. For the time being, think about your client, and do what is best for your client.

Meeting chairperson, Ghana AIDS Commission: In your reporting, there is a place for comments. Write out, "Of this distribution, this number came from [the other program]." Let that headache be the donor's headache. We need an element of flexibility in programming and getting the resources out there!

In this instant, higher-level personnel conveyed an objection to NGOs being exacting about data entry, because it is at odds with dexterous problem solving. The greater flexibility wished for by the higher levels and the strict adherence practised at the NGO level is reason for pause. Scholars of audit culture have taught us that calculative practices of measurement and ranking, operating as new forms of governance, will produce self-disciplined, accountable subjects (Shore and Wright 2015a, 2015b). Yet the governed are able to shift their behaviour to improve their assessment and, as Merry (2011) notes, "they may do so in ways not desired by the producer" of the technology (S90). Merry is referring specifically to actors' strategies to game the system, but what does it mean when the undesired behaviour is, instead, a strong adherence to the calculative practice itself?
Mark Schuller's (2012) useful concept of "trickle down imperialism" captures the nature of the kind of contradiction we see between Hope and its supervisors. ${ }^{7}$ Analysing how power works within the aid system in Haiti, Schuller (2012) describes the pattern whereby subordinates along the chain of command adhere ever more strictly to policy mandates down the chain to please their superiors, "using the implicit power relationship as justification" (183). The supervisors seem unaware of the contradiction. They say they want something more, without understanding the pressures for peer educators and NGOs to conform to standardised practices. Inequality sets the stage for a conservative interpretation trickling down the system (Schuller 2012).

Hope adhered strictly to $\mathrm{M} \& \mathrm{E}$ documentation to please its superiors. The threat of power in the form of lost funding (whether real or imagined) loomed overhead. For Hope, meeting these expectations meant renewed funding and possible consideration by USAID and the BINGO for a future program. For peer educators, it meant getting " $\mathrm{T}$ and $\mathrm{T}$ " and keeping their jobs. Spaces for critical discussion and alternative knowledge-making were therefore indirectly eroded. Contrary to some supervisors' views, NGO actors are not immature or uncreative. The social reality they face is much different from that of the BINGO, GAC and USAID. Further, the resources become scarcer further down the system, and in an under-resourced setting such as Ghana, where protocols are consuming, conservative adherence is oftentimes the only action possible.

These realities may also help to explain Hope staff's inability or reluctance to fully grasp and/or act on the complexities underlying peer educators' data collection, which can motivate cooking data. Hope did not have the power to set the payment amount peer educators received. Furthermore, the staff was already strapped for time, energy and resources, and it may have been easier to focus on executing the program as smoothly as possible rather than addressing deep structural issues. Prince and others may also have mistaken Hope staff's preoccupation with meeting expectations as not caring or respecting their ideas (as in Viola's case above). Aunty Phyllis and Hope staff did generally care about peer educators and had empathy for their experiences. Yet Hope's staff was immersed within an aid system that diverted attention away from doing things differently.

NGOs can, to some degree, be active agents in the system of inequality rather than objects of domination. Trickle-down imperialism triggered Hope (and other NGOs, as the above vignette indicates) to act more conservatively with $\mathrm{M} \& \mathrm{E}$ documentation than their superiors wanted and thereby adversely undermine their own 
autonomy. The Sheets did not abduct their agency or role in the program, however; they actively composed it, a characteristic of audit culture (Shore and Wright 2015b). Furthermore, M\&E documentation somewhat shaped subjectivity, aligning actors' work and worth with their meeting the Sheets' requirements (Shore and Wright 2015b). The Sheet was imposed and externally used and validated, but for some peer educators it also legitimised their accomplishments. Completing the Sheet could feel satisfying. For instance, peer educator Titus said it made him "feel good" to document his met targets. He dutifully documented his numbers when he got home each day; his notebook sat on a table by his front door, where he also proudly displayed BRIDGES education materials. Peer educators clearly liked to receive praise from Hope about their compliant documenting practices. Eli took pride in his sophisticated self-made Excel spreadsheets. While driving me to the trotro (minibus share taxi) station at one day's end, Eli expressed satisfaction with Hope's performance and its ability to report within deadlines unlike some other NGOs, two of which, he said, were reprimanded at a review meeting at the BINGO earlier that day.

A fundamental inequality is brought to the surface by the $\mathrm{M} \& \mathrm{E}$ documents. It reflects wider contradictions underlying development discourse and policy implementation, and specifically HIV policy and programming: partnership and participation is preached while donors retain control over funds. The ambiguity of "participation" and "partnership" has been the source of much critical discussion within the scholarly literature (Cornwall and Eade 2010; Esser 2015; Maes 2017; Mawuko-Yevugah 2014). "Partnership" denotes at least some shared control over the design and implementation of programs and policies. This paper has shown that, contrary to this image, $\mathrm{M} \& \mathrm{E}$ documentation is an important element that both elicits and constructs uneven control, an observation that is in line with the discrepancy between the rhetoric and reality of partnerships in development that other scholars have highlighted (Contu and Girei 2014; Cornwall and Eade 2010).

Blindness to the effects of documentation puts the onus for compliance and autonomy on individual Ghanaians. According to higher level personnel, the solution to austerity was more "capacity building". Certainly NGO members can benefit from greater training, but the shift of responsibility twice loaded (not only to comply closely with documentation terms, but also to be flexible and creative) doubly obscures underlying power dynamics. Akin to arguments made about metrics
(Merry 2011, 2016; Shore and Wright 2015a, 2015b), M\&E documentation shifts responsibility for governance from those in power to those who are governed; $\mathrm{M} \& \mathrm{E}$ documents are technologies that engage actors in governing themselves, a fact that neatly obscures the political and financial power of governing institutions like USAID. On another level, discourses of partnership, creativity, flexibility and the like gloss over the realities of inequality.

\section{Conclusion}

Multilateral-organisation-led efforts to harmonise and coordinate the global HIV response have shaped normative methods to assess interventions and workers, including standardised M\&E documentation, the demand for which is increasing. In the domain of HIV, and more widely, global health and development, evidence-based methods and reporting have become more dense, less so because they improve interventions and health, social, and economic problems and more so because they allow for uniformities across a complex terrain necessary for monitoring and controlling actions at a global level (Erikson 2012; see also Rottenburg 2009). By analysing the material production of such standardised translocal knowledge, this article has shown that M\&E documentation can operate as much more than its given purpose to demonstrate accountability and achievement. It can operate as a form of governance and power, determining where and to whom donor funding should flow, shaping users into self-managers, and in this case, inadvertently generating users' strict compliance with documentation expectations. The demand for standardised, evidence-based documentation can have unintended and adverse effects, including reinforcing unequal relations between donor and recipient countries, organisations - for instance, NGO, BINGO and donor - and personnel within and across these organisations. It is by attending to the ways particularly positioned users engage with $\mathrm{M} \& \mathrm{E}$ documentation that we gain insight into the unexpected ways that these effects can occur. As M\&E documentation demands continue to intensify, greater research is needed into actors' experience with documentation and its influence on the intervention landscape. Such studies may, like my own work, help to elucidate how social relations and roles in aid intervention are currently formed, and how certain divides may be deepened or challenged.

\section{Kathleen Inglis, PhD, Department of Sociology and Anthropology, Simon Fraser University, Burnaby, BC. Email:klinglis@sfu.ca.}




\section{Acknowledgements}

Research for this article was supported by a JosephArmand Bombardier Canada Graduate Scholarships Program Doctoral Scholarship from the Social Sciences and Humanities Research Council of Canada (\#7672009-7058) and a Doctoral Research Award from the International Development Research Centre (\#10669099906075-047).

\section{Notes}

1 Lorway and Khan (2014) and Shukla et al. (2016) are among the few that have addressed these issues.

2 For purposes of anonymity and confidentiality, the program has been given a fictional name, as have all individuals and organisations named except for USAID and the Ghana AIDS Commission (GAC).

3 Conflating NGOs with civil society is a prevailing view in policy writing, but not the sole one (Harsh et al. 2010, 255). A critical discussion of the meanings of civil society is beyond the scope of this paper.

4 Counting NGOs is a problematic affair. Doing so likely overlooks short-lived organisations, new organisations and organisations that have fallen through the record-keeping and registration cracks, and a lack of universal consensus on what an NGO "is" may lead to discrepant results (Watkins et al. 2012). At the risk of participating in a problematic practice, I cite one count of the NGOs in Ghana to give some sense of their substantial presence.

5 See also Biruk (2012, 362), who makes this claim, not specifically about monitoring and evaluation but about AIDS research "forms or products," that is, documents.

6 The Sheet reads "ABS" instead of "ABC"; typo in the original.

7 Although Schuller's (2012) concept of trickle-down imperialism is useful here, it is a concept I critique elsewhere as ultimately too linear (Inglis 2018).

\section{References}

Adams, Vincanne, ed. 2016. Metrics: What Counts in Global Health. Durham: Duke University Press. https://doi.org/ 10.1215/9780822374480.

Adams, Vincanne, Michelle Murphy, and Adele E. Clarke. 2009. "Anticipation: Technoscience, Life, Affect, Temporality.” Subjectivity: International Journal of Critical Psychology 28(1): 246-265.

Awuah-Werekoh, Kwasi. 2014. "Accountability Systems of Non-Governmental Organisations (NGOs): Case Study from Ghana." $\mathrm{PhD}$ dissertation, Birmingham Business School, College of Social Sciences, University of Birmingham.

Bell, Catherine. 2009. Ritual: Perspectives and Dimensions. New York: Oxford University Press.

Biruk, Crystal. 2012. "Seeing Like a Prevention Project: Producing 'High Quality' Data in AIDS Research in Malawi.” Medical Anthropology 31(4): 347-366. https:// doi.org/10.1080/01459740.2011.631960.

—. 2018. Cooking Data: Culture and Politics in an African Research World. Durham: Duke University Press.
Contu, Alessia, and Emanuela Girei. 2014. "NGOs

Management and the Value of 'Partnerships' for Equality in International Development: What's in a Name?" Human Relations 67(2): 205-232. https://doi.org/10.1177/ 0018726713489999.

Cooke, Edgar, Sarah Hague, and Andy McKay. 2016. The Ghana Poverty and Inequality Report. https:// www.unicef.org/ghana/ Ghana_Poverty_and_Inequality_Analysis_

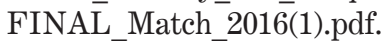

Cornwall, Andrea, and Deborah Eade, eds. 2010. Deconstructing Development Discourse: Buzzwords and Fuzzwords. Bourton-on-Dunsmore: Practical Action Publishing. https://doi.org/10.3362/9781780440095.

Coyle, Susan L., Robert F. Boruch, and Charles F. Turner, eds. 1991. Evaluating AIDS Prevention Programs. Washington: National Academy Press.

De Lay, Paul, and Valerie Manda. 2004. "Politics of Monitoring and Evaluation: Lessons from the AIDS Epidemic.” New Directions for Evaluation 103: 13-31. https://doi.org/ 10.1002/ev.120.

Ebrahim, Alnoor. 2003. "Accountability in Practice: Mechanisms for NGOs.” World Development 31(5): 813829.

Erikson, Susan L. 2012. "Global Health Business: The Production and Performativity of Statistics in Sierra Leone and Germany." Medical Anthropology 31(4): 367-384. https://doi.org/10.1080/01459740.2011.621908.

Esser, Daniel E. 2015. "Elusive Accountabilities in the HIV Scale-Up: 'Ownership' as a Functional Tautology." In HIV Scale-Up and the Politics of Global Health, ed. N.J. Kenworthy and R. Parker, 43-56. London: Routledge.

Fisher, Celia B., Gala True, Leslie Alexander, and Adam L. Fried. 2013. "Moral Stress, Moral Practice, and Ethical Climate in Community-Based Drug-Use Research: Views from the Front Line." AJOB Primary Research 4(3): 27 38. https://doi.org/10.1080/21507716.2013.806969.

Ghana AIDS Commission. 2015. Country AIDS Response Program Report - Ghana. http://www.unaids.org/sites/ default/files/country/documents/ GHA narrative report 2015.pdf.

Harper, Richard. 2000. "The Social Organization of the IMF's Mission Work: An Examination of International Auditing." In Audit Cultures: Anthropological Studies in Accountability, Ethics, and the Academy, ed. Marilyn Strathern, 21-53. London: Routledge.

Harsh, Matthew, Paul Mbatia, and Wesley Shrum. 2010. "Accountability and Inaction: NGOs and Resource Lodging in Development." Development and Change 41(2): 253-278. https://doi.org/10.1111/j.1467-7660.2010.01641.x.

Hodžić, Saida. 2016. The Twilight of Cutting: African Activism and Life after NGOs. Oakland: University of California Press.

Hull, Matthew. 2012. "Documents and Bureaucracy." Annual Review of Anthropology 41(1): 251-267. https://doi.org/ 10.1146/annurev.anthro.012809.104953.

Inglis, Kathleen. 2018. "The Social Life of Monitoring and Evaluation: An Ethnography of the Monitoring and Evaluation of an HIV/AIDS Prevention Program in Ghana.” PhD dissertation, Simon Fraser University, 2018. 
Justice, Judith. 1986. Policies, Plans, and People. Berkeley: University of California Press.

Karimi, Faith. 2012. "Obama Hails Ghana as a 'Model of Democracy’ in Africa.” CNN, March 29. http:// www.cnn.com/2012/03/08/world/africa/obama-ghanapresident/index.html.

Kingori, Patricia, and René Gerrets. 2016. "Morals, Morale and Motivations in Data Fabrication: Medical Research Fieldworkers' Views and Practices in Two Sub-Saharan African Contexts." Social Science \& Medicine 166: 150-159. https://doi.org/10.1016/j.socscimed.2016.08.019.

Latour, Bruno. 1987. Science in Action: How to Follow Scientists and Engineers through Society. Cambridge: Harvard University Press.

Lorway, Robert, and Shamshad Khan. 2014. "Reassembling Epidemiology: Mapping, Monitoring and Making-Up People in the context of HIV Prevention in India." Social Science \& Medicine 112: 51-62. https://doi.org/10.1016/ j.socscimed.2014.04.034.

Maes, Kenneth. 2017. The Lives of Community Health Workers. New York: Routledge.

Mawuko-Yevugah, Lord. 2014. Reinventing Development: Aid Reform and Technologies of Governance in Ghana. Surrey: Ashgate Publishing.

Merry, Sally Engle. 2011. "Measuring the World: Indicators, Human Rights, and Global Governance." Current Anthropology 52(S3): S83-S95. https://doi.org/10.1086/ 657241.

- 2016. The Seductions of Quantification: Measuring Human Rights, Gender Violence, and Sex Trafficking. Chicago: University of Chicago Press.

Miller, Peter, and Nikolas Rose. 1990. "Governing Economic Life.” Economy and Society 19(1): 1-31. https://doi.org/ 10.1080/03085149000000001.

Power, Michael. 1997. The Audit Society: Rituals of Verification. Oxford: Oxford University Press.

Rose, Nicolas. 1989. Governing the Soul: The Shaping of the Private Self. London: Routledge.

Rottenburg, Richard. 2009. Far-Fetched Facts: A Parable of Development Aid, translated by Allison Brown and Tom Lampert. Cambridge: MIT Press. https://doi.org/10.7551/ mitpress/9780262182645.001.0001.

Rottenburg, Richard, Sally Engle Merry, Sung-Joon Park, and Johanna Mugler, eds. 2015. The World of Indicators: The Making of Governmental Knowledge through Quantification. Cambridge and New York: Cambridge University Press. https://doi.org/10.1017/ CB09781316091265.

Rugg, Deborah, Michel Carael, Jan Ties Boerma, and John Novak. 2004. "Global Advances in Monitoring and Evaluation of HIV/AIDS: From AIDS Case Reporting to Program Improvement." New Directions for Evaluation 103: 33-48. https://doi.org/10.1002/ev.121.
Sangaramoorthy, Thurka. 2012. "Treating the Numbers: HIV/ AIDS Surveillance, Subjectivity, and Risk.” Medical Anthropology 31(4): 292-309. https://doi.org/10.1080/ 01459740.2011.622322.

Schuller, Mark. 2012. Killing with Kindness: Haiti, International Aid and NGOs. New Jersey: Rutgers University Press.

Shore, Cris, and Sharon Wright. 2015a. "Audit Cultures Revisited: Ratings, Rankings and the Reassembling of Society." Cultural Anthropology 56(3): 421-444.

Shore, Cris, and Susan Wright. 2015b. "Governing by Numbers: Audit Culture, Rankings and the New World Order." Social Anthropology 23(1): 22-28. https://doi.org/ 10.1111/1469-8676.12098.

Shukla, Anuprita, Paul Teedon, and Flora Cornish. 2016. "Empty Rituals? A Qualitative Study of Users' Experience of Monitoring and Evaluation Systems in HIV Interventions in Western India." Social Science \& Medicine 168: 7-15. https://doi.org/10.1016/ j.socscimed.2016.08.041.

Strathern, Marilyn, ed. 2000. Audit Cultures: Anthropological Studies in Accountability, Ethics, and the Academy. London: Routledge. https://doi.org/10.4324/9780203449721.

Timmermans, Stefan, and Steven Epstein. 2010. "A World of Standards but Not a Standard World: Towards a Sociology of Standards and Standardization." Annual Review of Sociology 36(1): 69-89. https://doi.org/10.1146/ annurev.soc.012809.102629.

True, Gala, Leslie B. Alexander, and Kenneth A. Richman. 2011. "Misbehaviors of Front-Line Research Personnel and the Integrity of Community-Based Research." Journal of Empirical Research on Human Research Ethics 6(2): 3-12. https://doi.org/10.1525/jer.2011.6.2.3.

United States Agency for International Development. 2017. "Budget: The Fiscal Year (FY) 2018 Budget Request for USAID Defends Our National Security Interests and Addresses the Challenges to American Leadership Abroad." https://www.usaid.gov/results-and-data/budgetspending.

Watkins, Susan Cotts, Ann Swidler, and Thomas Hannan. 2012. "Outsourcing Social Transformation: Development NGOs as Organizations." Annual Review of Sociology 38(1): 285-315. https://doi.org/10.1146/annurev-soc-071811145516.

World Bank Group. 2017. "Prevalence of HIV, Total (\% of Population Ages 15-49).” https://data.worldbank.org/ indicator/SH.DYN.AIDS.ZS.

World Health Organization. 2017. “'Three Ones’ Agreed by Donors and Developing Countries.” http://www.who.int/ 3by5/newsitem $9 /$ en/.

Yarrow, Thomas. 2011. Development Beyond Politics: Aid, Activism and NGOs in Ghana. New York: Palgrave Macmillan. 